\title{
Preparation of resistant sweet potato starch by steam explosion technology using response surface methodology
}

\author{
Guanglei Li ${ }^{\star}$, Lingling Pang, Fei Li, Jie Zeng and Junliang Sun \\ School of Food Science, Henan Institute of Science and Technology, Xinxiang, 453003, China
}

*For correspondence: Email: Igl70_hist@163.com; Tel: +863733693693

Sent for review: 17 December 2016

Revised accepted: 22 April 2017

\begin{abstract}
Purpose: To obtain the optimal conditions and analyze the structure, gelatinization, and digestion characteristics of resistant sweet potato starch prepared by steam explosion (SE) technology.

Methods: A response surface method was used to investigate the effects of explosion pressure, pressure-holding time and autoclaving time on digestion resistance of sweet potato starch. The resulting resistant sweet potato starch was identified by Fourier transform infrared spectroscopy (FT-IR), differential scanning calorimetry (DSC), and for in vitro starch digestion rate.

Results: The optimum preparation conditions for resistant sweet potato starch were explosion pressure, 2.1 MPa; pressure-holding time, $56 \mathrm{~s}$; and autoclaving time, $26 \mathrm{~min}$. Under these conditions, digestion resistance of sweet potato starch of up to $37.73 \pm 0.86 \%$ was obtained. Infra-red spectra indicate that no new chemical groups appeared in the structure of the resistant starch. Furthermore, a gelatinisationinduced endothermic peak was observed in the DSC thermogram of potato starch at about $160^{\circ} \mathrm{C}$. The in vitro digestion data showed that the in vitro digestion rate had undergone a significant decrease.

Conclusion: Sweet potato starch treated by SE and autoclaving has lower digestibility and therefore, can potentially be used in food or medicine for diabetic patients.
\end{abstract}

Keywords: Resistant sweet potato starch, Steam explosion, Digestion resistance, Starch digestion rate, Response surface methodology

Tropical Journal of Pharmaceutical Research is indexed by Science Citation Index (SciSearch), Scopus, International Pharmaceutical Abstract, Chemical Abstracts, Embase, Index Copernicus, EBSCO, African Index Medicus, JournalSeek, Journal Citation Reports/Science Edition, Directory of Open Access Journals (DOAJ), African Journal Online, Bioline International, Open-J-Gate and Pharmacy Abstracts

\section{INTRODUCTION}

Steam-explosion (SE) treatment involves placing raw materials in a high-temperature, highpressure environment where the materials swell due to the presence of the overheated liquid and then fill their pores with steam. Then when the high pressure is instantly (within $0.00875 \mathrm{~s}$ ) relieved, the overheated liquid in the pores is vaporized and undergoes quasi-instantaneous volumetric expansion, resulting in cell membrane fracture. The cell walls are thus fractured and, as a result, contain many pores through which micro-molecular substances are released from the cells $[1,2]$. Owing to various chemical and physical changes that can occur in materials, only upon application of high-temperature steam, and without the use of additional chemical substances, SE technology has been considered as a promising pre-treatment method for transforming biomass resources [3].

Resistant starch is indigestible in the human digestive tract but can be glycolysed by microorganisms in the human colon. In addition, resistant starch also has various functions including the regulation of blood sugar level and prevention of cardio-cerebrovascular diseases 
and colorectal cancer. As a new-type of functional food material with low calorific value, resistant starch has been a research focus for those interested in protective food development $[4,5]$.

Based on a single factor experiment, the influences of various factors, including explosion pressure, pressure-holding time, and autoclaving time, on the digestion-resistance characteristics were studied by using a response surface analysis (RSA). The preparation technology used for the resistant sweet potato starch via SE technology was optimised. The structure, gelatinisation, and digestibility characteristics of the resulting resistant sweet potato starch were measured by using infrared spectroscopy, differential scanning calorimetry, and in vitro digestion.

By doing so, the authors attempted to provide references for the production and popularisation of sweet potato starch with high-level antidigestion characteristics in a medicinal context.

\section{EXPERIMENTAL}

\section{Materials}

Sweet potato starch was purchased from Agriculture Development Limited Company, Hezai, Henan; a-amylase and glucoamylase were provided by Fuyuan Biological Science and Technology Limited Company, Zhengzhou, Henan. The other chemicals were of analytical grade.

\section{Preparation of resistant sweet potato starch by SE technology}

Sweet potato starch $(200 \mathrm{~g})$ was added to a cylinder (QBS-80-type test-bed for steamexplosions, Zhengdao Heavy Machinery Factory, Hebi, Henan Province, China). After covering the cylinder with a lid, high-temperature saturated seam was pumped into the cylinder to increase the pressure to $1.2 \mathrm{MPa}$. After holding for $40 \mathrm{~s}$, the pneumatic valve was opened for $0.00875 \mathrm{~s}$ to relieve the pressure and explode the materials. Finally, the materials extruded from the cylindrical cavity were collected [6]. Sweet potato starch samples pre-treated by SE technology were suspended in water $(1: 3.5, \mathrm{w} / \mathrm{v})$, and autoclaved at $121{ }^{\circ} \mathrm{C}$ for $30 \mathrm{~min}$. Then, the samples were cooled and stored at $4{ }^{\circ} \mathrm{C}$ in a refrigerator for $24 \mathrm{~h}$. After being dried at $80^{\circ} \mathrm{C}$, the samples were ground to a fineness enabling them to pass through a $200 \mu \mathrm{m}$ square aperture sieve [7].

\section{Measurement of starch digestion resistance}

Starch digestion resistance was measured according to Goni et al [8] and Li et al [9]. The reducing sugar content of the samples was determined by 3, 5-dinitrosalicylic acid (DNS) method [10]. Starch digestion resistance $(R)$ was calculated as shown in Equation 1.

$\mathrm{R}=(\mathrm{RS} / \mathrm{SD}) 100$

where RS is the resistant starch content, and SD is the sweet potato total starch content.

\section{Single-factor experiment}

The effects of the five reacting factors (explosion pressure, explosion time, sample starch content, autoclaving time, and cooling time) on the digestibility of sweet potato starch were studied by single factor experiment design. Each treatment was conducted three times and the mean value calculated.

\section{Response surface experiment}

The response surface experiment for the three factors at their three levels was designed by Design-Expert (Version 7.1.3) software according to the method in Li et al. [11]. Starch digestion resistance was used as the response value. The model can be expressed as a quadratic polynomial, a least-squares, or best-fit equation (see Equation 2).

$$
Y=b_{0}+\sum_{n=1}^{3} b_{n} x_{n}+\sum_{n=1}^{3} b_{n n} x_{n}^{2}+\sum_{n \neq m-1}^{3} b_{t m} x_{n} x_{m} \cdots \cdots(2)
$$

where $Y$ is the response value; $b_{0}, b_{n}, b_{n n}$, and $b_{n m}$ refer to the coefficients, $x_{n}, x_{m}(n \neq m)$ are the coded values of the independent variable. The goodness-of-fit of the polynomial was expressed by its coefficient of determination $R^{2}$. Its statistical significance was tested by $F$-test. Design-Expert (Version 7.1.3) software was used for the analysis of variance [12].

\section{Fourier transform infrared spectroscopy (FT- IR)}

FT-IR (Nicolet 470; Perkin Elmer Inc., Waltham, MA, USA) was used to determine the structure of the sweet potato starch according to the method described in Marzieh et al [9].

\section{Differential scanning calorimetry (DSC)}

Differential scanning calorimeter (DSC, TA instruments Waters LLC, New Castle, DE, USA) equipped with a thermal analysis data station, 
was used to determine the thermal properties of the starch according to the method adopted by Marzieh et al [9].

\section{Determination of starch digestion rate}

The starch digestion rate was measured by the method described by Li et al [11]. The reducing sugar content was determined by DNS method and the starch hydrolysis rate $(S)$ was calculated by using Equation 3 (after Zabidi et al [13]).

Starch hydrolysis rate $(\%)=\frac{\mathrm{G}_{t} \times 25 \times 0.9}{200} \times 100$.

where $G_{t}$ denotes the glucose content after conducting amylase hydrolysis for $t$ minutes.

\section{Statistical analysis}

Statistical analysis was carried out using DPS 7.05 software (Zhejiang University, Hangzhou, China). All measurements were repeated three times and mean \pm standard deviation data were presented. Statistical comparisons were carried out using the Dixon test, and $p<0.05$ was considered statistically significant.

\section{RESULTS}

\section{Single factor experimental data}

The following conditions were applied (except to research objective itself): an explosion pressure of $2.0 \mathrm{MPa}$, a pressure-holding time of $60 \mathrm{~s}$, a starch samples content of $25 \%$, an autoclaving time of $30 \mathrm{~min}$, and a cooling time of $24 \mathrm{~h}$. Table 1 showed the results thus obtained.

The starch digestion resistance $(R)$ of sweet potato starch increased with increasing explosion pressure, pressure-holding time, and starch content. However, when the SE pressure, holding time, and starch content separately exceeded $2.0 \mathrm{MPa}, 60 \mathrm{~s}$, and $30 \%$, the $R$ value was maximised. With increased autoclaving and cooling time, the indigestibility of sweet potato starch increased, however, when the autoclaving time reached $30 \mathrm{~min}$, and the cooling time was
$24 \mathrm{~h}$, the rate of increase of starch indigestibility decreased.

\section{Response surface analysis}

According to the single factor experiment results, and considering the starch digestion resistance and economic cost, the mid-levels of each independent variable in this response surface experiment were set as follows: explosion pressure 2.0 MPa, pressure-holding time $60 \mathrm{~s}$, and autoclaving time $30 \mathrm{~min}$. The three influence factors were represented by: $X_{1}, X_{2}$, and $X_{3}$, respectively. The low, middle, and high, experimental levels of each independent variable were separately coded as: $-1,0$, and 1 (see Table 2).

The experiment design followed typical protocols for a central combination of response surface methodologies. Each treatment was replicated three times, and the average value was obtained. The design of the experiments is summarised in Table 3.

A multiple regression analysis was performed according to the experimental data by using Design-Expert software: a quadratic regression equation with starch digestion resistance as its objective function was acquired.

$$
\begin{aligned}
& \mathrm{Y}=-92.7087+102.0044 \times \mathrm{X}_{1}+0.1816 \times \mathrm{X}_{2}+ \\
& 1.2272 \times \mathrm{X}_{3}+0.2184 \times \mathrm{X}_{1} \mathrm{X}_{2}-0.4531 \times \mathrm{X}_{1} \mathrm{X}_{3}+ \\
& 0.0132 \times \mathrm{X}_{2} \mathrm{X}_{3}-24.2574 \times \mathrm{X}_{1}^{2}-0.0088 \times \mathrm{X}_{2}^{2}- \\
& 0.0193 \times X_{3}^{2}
\end{aligned}
$$

The regression analysis revealed that the starch digestion resistance of the sweet potato starch was significantly influenced by explosion pressure. Variance analysis showed that the lack of fit $(F=0.2540)$ of the test to the regression equation was insignificant, indicating that those unknown factors exerted a negligible influence on the experimental results (Table 4).

In addition, the regression equation was statistically significant $(p<0.01)$. There was $98.88 \%$ of the fluctuation $\left(R^{2}=0.9888\right)$ of the

Table 1: Single-factor experiment protocols and results

\begin{tabular}{lc||cc||cc||cc|cc}
\hline $\begin{array}{l}\text { SE } \\
\text { pressure } \\
\text { (MPa) }\end{array}$ & $\begin{array}{c}\mathbf{R} \\
(\mathbf{\%})\end{array}$ & $\begin{array}{c}\text { Holding } \\
\text { time (S) }\end{array}$ & $\begin{array}{c}\mathbf{R} \\
\mathbf{( \% )}\end{array}$ & $\begin{array}{c}\text { Starch } \\
\text { content } \\
(\%)\end{array}$ & $\begin{array}{c}\mathbf{R} \\
(\%)\end{array}$ & $\begin{array}{c}\text { Autoclaving } \\
\text { time (min) }\end{array}$ & $\begin{array}{c}\mathbf{R} \\
(\%)\end{array}$ & $\begin{array}{c}\text { Cooling } \\
\text { time (h) }\end{array}$ & $\begin{array}{c}\mathbf{R} \\
(\%)\end{array}$ \\
\hline 0 & 7.36 & 0 & 7.36 & 15 & 26.36 & 10 & 19.22 & 6 & 20.34 \\
1.2 & 17.85 & 20 & 15.81 & 20 & 31.55 & 20 & 28.93 & 12 & 26.04 \\
1.6 & 25.27 & 40 & 26.53 & 25 & 34.15 & 30 & 35.43 & 18 & 31.59 \\
2.0 & 34.18 & 60 & 34.55 & 30 & 33.48 & 40 & 36.56 & 24 & 35.19 \\
2.4 & 29.13 & 80 & 28.46 & 35 & 31.20 & 50 & 36.89 & 30 & 36.59 \\
\hline
\end{tabular}


Table 2: Variables and their levels for central composite design

\begin{tabular}{lcccc}
\hline \multirow{2}{*}{ Variable } & \multirow{2}{*}{ Symbol } & \multicolumn{3}{c}{ Coded-variable level } \\
\cline { 3 - 5 } & & $\mathbf{- 1}$ & $\mathbf{0}$ & $\mathbf{1}$ \\
\hline SE pressure (MPa) & $\mathrm{X}_{1}$ & 1.6 & 2.0 & 2.4 \\
Holding time (S) & $\mathrm{X}_{2}$ & 40 & 60 & 80 \\
Autoclaving time (min) & $\mathrm{X}_{3}$ & 20 & 30 & 40 \\
\hline
\end{tabular}

Table 3: Central composite design arrangement and response

\begin{tabular}{lcccc}
\hline \multirow{2}{*}{ Run } & \multicolumn{3}{c}{ Variable level } & Response \\
\cline { 2 - 4 } & $\boldsymbol{X}_{\mathbf{1}}$ & $\boldsymbol{X}_{\mathbf{2}}$ & $\boldsymbol{X}_{\mathbf{3}}$ & $(\mathbf{R} \%)$ \\
\hline 1 & 2.0 & 40 & 40 & 30.79 \\
2 & 2.4 & 60 & 40 & 25.56 \\
3 & 2.0 & 60 & 30 & 35.15 \\
4 & 2.0 & 60 & 30 & 36.82 \\
5 & 1.6 & 40 & 30 & 28.63 \\
6 & 2.0 & 80 & 20 & 30.25 \\
7 & 2.4 & 80 & 30 & 31.81 \\
8 & 2.0 & 60 & 30 & 35.74 \\
9 & 1.6 & 60 & 40 & 28.74 \\
10 & 1.6 & 80 & 30 & 27.32 \\
11 & 2.4 & 40 & 30 & 29.86 \\
12 & 2.0 & 80 & 40 & 33.05 \\
13 & 2.4 & 60 & 20 & 31.44 \\
14 & 1.6 & 60 & 20 & 28.66 \\
15 & 2.0 & 40 & 20 & 29.93 \\
\hline
\end{tabular}

response value (starch digestion resistance) explained by changes in the selected variables (i.e., explosion pressure, pressure-holding time, and autoclaving time). Hence, the regression equation represented a good fit to the chosen experimental conditions with acceptably low test errors.

\section{Response surface plots}

The response surface and contour plots charted using Design-Expert software showed the influence of each factor on the digestion resistance of starch. From Figure 1, the influence of the interaction of explosion pressure and holding time and their combined effects on the indigestibility of sweet potato starch was demonstrated.

From Figure 1, when the autoclaving time was at its mid-level value of $30 \mathrm{~min}$, the interaction of the SE pressure and holding time was apparent. Moreover, the digestion resistance of the sweet potato starch increased with increasing SE pressure within the range from $1.6 \mathrm{MPa}$ to 2.2 $\mathrm{MPa}$; however, when the explosion pressure exceeded 2.2 MPa, digestion resistance of the sweet potato starch decreased.

Table 4: ANOVA for the fitted model

\begin{tabular}{lccccc}
\hline Source & $\begin{array}{c}\text { Sum of } \\
\text { squares }\end{array}$ & $\mathbf{d}_{\mathbf{f}}$ & Mean square & F value & Prob $>\mathbf{F}$ \\
\hline Model & 235.42 & 9 & 26.16 & 49.06 & 0.0002 \\
Residual & 2.67 & 5 & 0.53 & & \\
Lack of Fit & 0.82 & 1 & 0.82 & 1.77 & 0.2540 \\
Pure error & 1.85 & 4 & 0.46 & & \\
Cor total & 238.09 & 14 & & \\
\hline
\end{tabular}
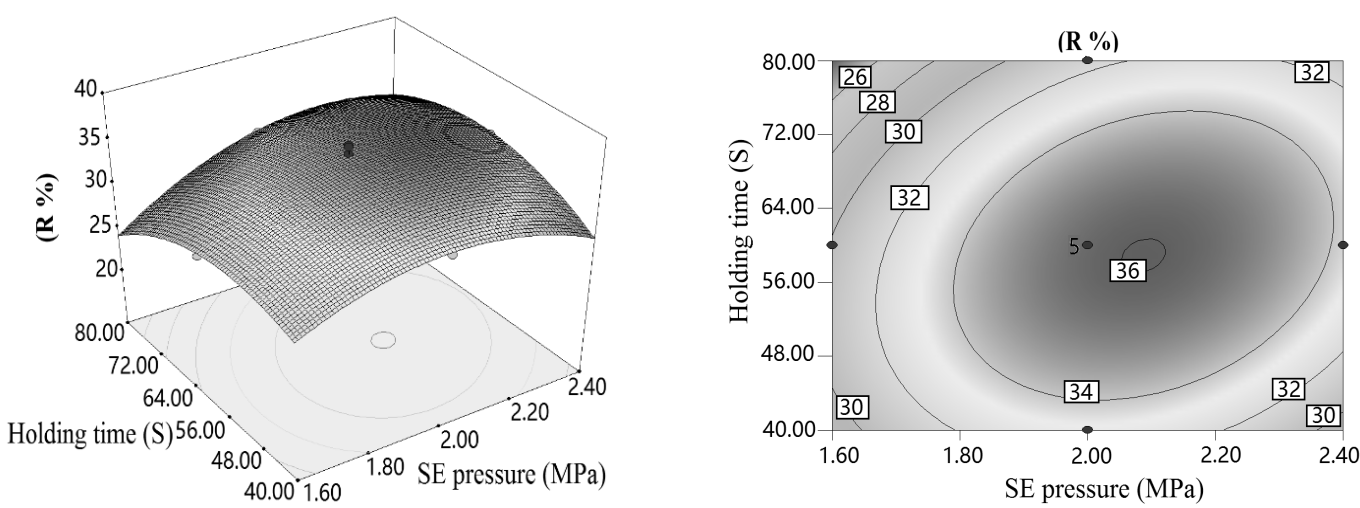

Figure 1: Effect of SE pressure and holding time on starch indigestibility of sweet potato starch 


\section{Verification of the process}

Within the range of each selected factor, the optimum conditions of the resistant sweet potato starch were obtained according to the regression model and analysis by Design-Expert software. The optimum conditions were as follows: explosion pressure 2.1 $\mathrm{MPa}$, pressure-holding time $56 \mathrm{~s}$, and autoclaving time $26 \mathrm{~min}$.

Under these conditions, the starch digestion resistance was $37.73 \pm 0.86 \%$, which was close to the predicted value of $38.21 \%$. This indicated that the model showed a good fit to reality and indicated its validity.

\section{Infrared scanning analysis}

The IR spectra of sweet potato starch, sweet potato starch pre-treated by SE technology, and resistant sweet potato starch $(R=37.73 \%)$ are shown in Figure 2.

The primary characteristic peaks of the infrared spectra of the sweet potato starch treated by SE and autoclaving were basically coincident with each other and no new absorption peaks appeared. This suggested that no new groups were developed in the resistant starch treated by SE or autoclaving, so the chemical structures of those starches remained unchanged.

\section{Thermal characteristics}

The DSC curves of sweet potato starch, sweet potato starch pre-treated by SE technology, and resistant sweet potato starch $(R=37.73 \%)$ are shown in Figure 3.

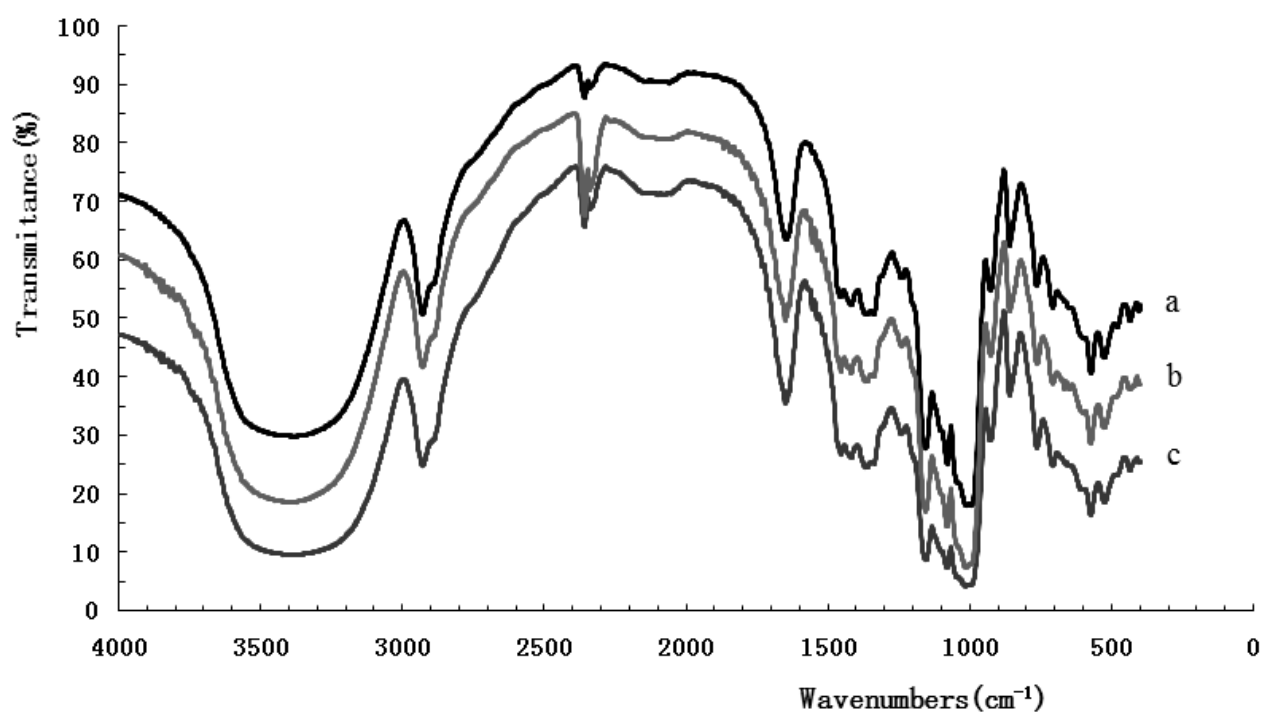

Figure 2: IR spectra of sweet potato starch samples. Key: $a=$ sweet potato starch; $b=$ sweet potato starch pretreated by $S E ; c=$ resistant sweet potato starch

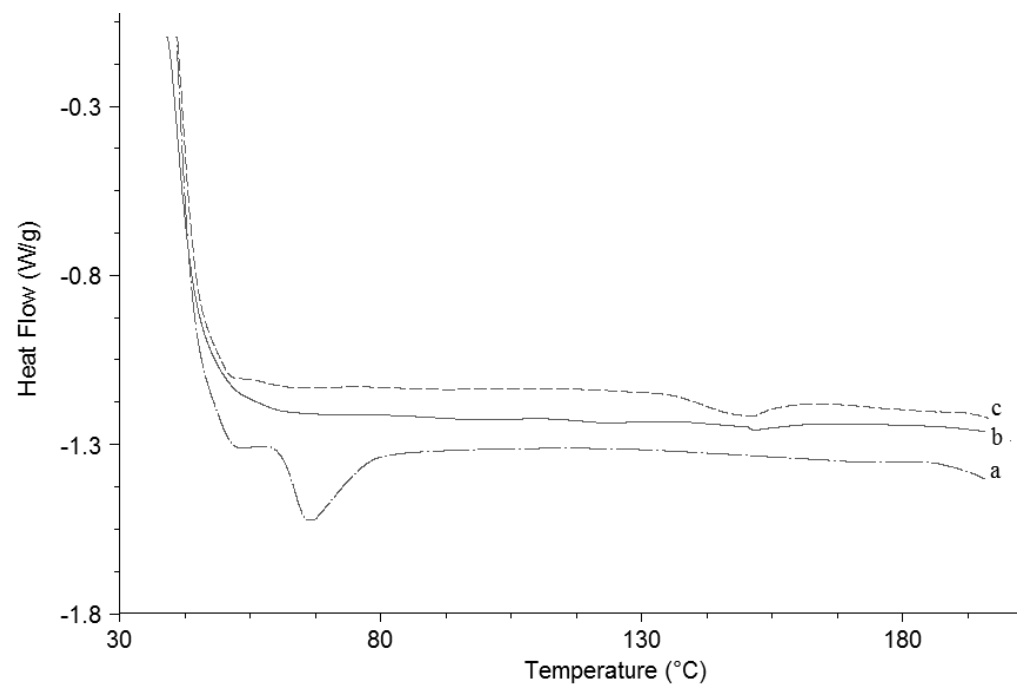

Figure 3: DSC thermogramss of the starch samples. Key: $a=$ sweet potato starch; $b=$ sweet potato starch pre-treated by $S E ; c=$ resistant sweet potato starch 
The DSC curve of sweet potato starch exhibited a small endothermic peak at $70{ }^{\circ} \mathrm{C}$ and then tended to be steady within the range from $40^{\circ} \mathrm{C}$ to and $190{ }^{\circ} \mathrm{C}$; however, the DSC curve of the sweet potato starch specimen treated by the proposed SE technology was shown to have been linear and flat, without the presence of any endothermic peaks, which suggested that the starch specimen had been completely gelatinised. The resistant starch made by using SE exhibited a gelatinisation-induced endothermic peak at about $160{ }^{\circ} \mathrm{C}$, which was caused by heat-absorption during the fusion of amylose crystals.

\section{Determination of in vitro digestion rate}

The in vitro digestion rates of sweet potato starch, sweet potato starch pre-treated by SE technology, and resistant sweet potato starch ( $R$ $=37.73 \%$ ) were investigated (Figure 4) with reference to fresh white bread as a benchmark. The in vitro digestion rate was defined as the percentage of starch hydrolysis at various times.

From Figure 4, the hydrolysis rates of sweet potato starch rapidly increased during the first $30 \mathrm{~min}$ and remained constant thereafter. The sweet potato starch could be hydrolysed to glucose by amylase.

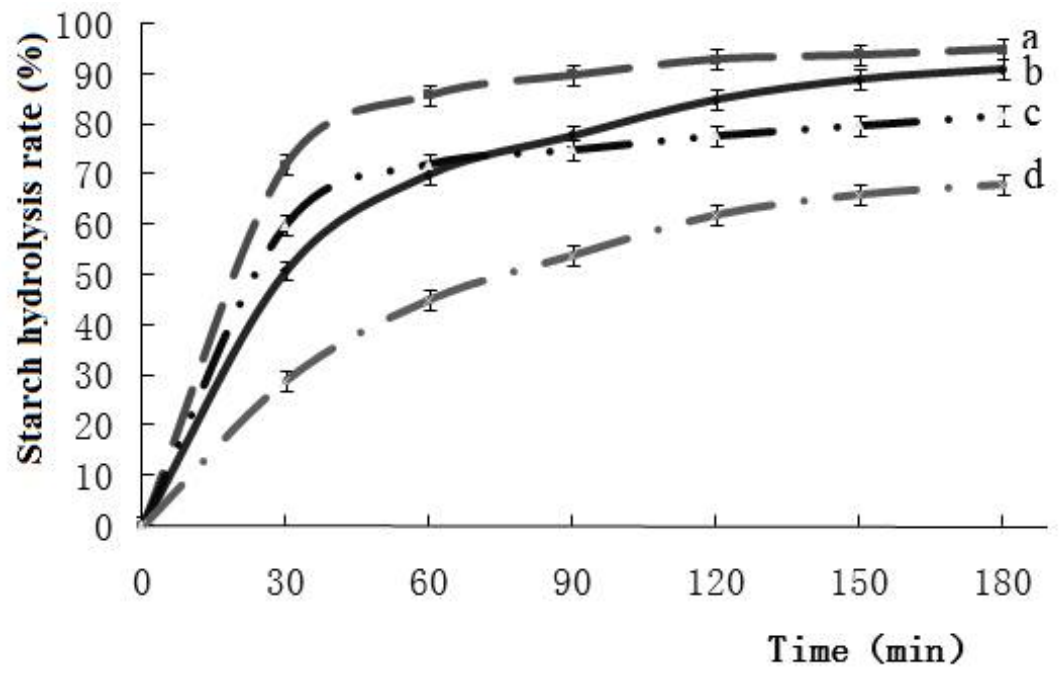

Figure 4: In vitro starch hydrolysis rate of the starch samples. Key: a = sweet potato starch; b-fresh white bread; $\mathrm{c}=$ sweet potato starch pre-treated by SE; $\mathrm{d}=$ resistant sweet potato starch

The resistant sweet potato starch $(R=37.73 \%)$ showed slower absorption than sweet potato starch, fresh white bread, and sweet potato starch pre-treated by SE technology. The rate of hydrolysis of resistant sweet potato starch increased slowly, and continually, compared to that of other samples. After the sweet potato starch had been treated by the proposed SE technology and autoclaving, the combination of amylase and starch was hindered because crystal bundle structures of short-chain starch were formed in the starch molecules. Therefore, the digestive ability of the starch significantly decreased.

\section{DISCUSSION}

Recent studies have shown that resistant starch cannot be digested by the small intestine and thus produce glucose, while part thereof can be fermented by intestinal microbial communities in the large intestine so as to produce multiple short-chain fatty acids which tend to improve the intestinal environment. Resistant starch, with its extremely low heat content, plays a physiological function similar to that of dietary fibre (DF) when added to food as a low-heat-content additive. More importantly, resistant starch also has various functions including the regulation of blood sugar level and prevention of cardiovascular and cerebrovascular diseases, colon cancer, and colorectal cancer. Therefore, resistant starch exhibits more potential benefits to the health care profession than DF [12].

The internal structures of the starch granules were damaged after sweet potato starch was treated by use of the proposed SE technology. In addition, the molecular chains of the amylose were degraded, and expansion and fracture occurred in parts of the amylopectin crystals. Therefore, there was a larger amount of shortchain amylose and amylopectin present in the cooled starch samples, which was of benefit to the generation of SDS and RS. SDS can be digested slowly to release glucose at a constant rate so as to maintain a low risk of hypoglycaemia, while RS is only fermented by microorganisms in the large intestine to produce 
short-chain fatty acids which are conducive to intestinal health. Therefore, the nutritional quality of the resistant sweet potato starch prepared by using SE technology was largely improved.

\section{CONCLUSION}

The optimum conditions for preparing resistant sweet potato starch by using steam explosion technology were obtained by using a response surface method. The nutritional quality of sweet potato starch treated with the proposed SE technology and autoclaving was improved significantly and showed a lower rate of in vitro starch hydrolysis. Therefore, resistant sweet potato starch offers potential applications in the health food, and pharmaceutical, industries.

\section{DECLARATIONS}

\section{Acknowledgement}

This study was funded by Science and Technology Research Project of Henan Province (no. 172102110164), and Major Breeding Project of Henan Institute of Science and Technology (no. 2013ZD04).

\section{Conflict of Interest}

No conflict of interest associated with this work.

\section{Contribution of Authors}

The authors declare that this work was done by the authors named in this article and all liabilities pertaining to claims relating to the content of this article will be borne by them.

\section{Open Access}

This is an Open Access article that uses a funding model which does not charge readers or their institutions for access and distributed under the terms of the Creative Commons Attribution License (http://creativecommons.org/licenses/by/ 4.0) and the Budapest Open Access Initiative (http://www.budapestopenaccessinitiative.org/rea d), which permit unrestricted use, distribution, and reproduction in any medium, provided the original work is properly credited.

\section{REFERENCES}

1. Konstantin GB, Anna A K, Maria A G, Janis G, Sergey S, Dmitry G, Ivan NZ. Application of steam explosion as a method of wood matrix thermochemical activation. J Indian Acad Wood Sci 2016; 13(1): 82-89.
2. Marzieh S, Maryam MK, Hamid Z, Ilona SH, Keikhosro K. Techno-economical study of biogas production improved by steam explosion pretreatment. Bioresour Technol 2013; 148: 53-60.

3. Mclntosh S, Zhanying Z, Palmer J, Hengho W, Doherty $W$, Vancov, T. Pilot-scale cellulosic ethanol production using eucalyptus biomass pre-treated by dilute acid and steam explosion. Biofuels Bioprod Biorefin 2016; 10(4): 346-358.

4. Chung C, Sanguansri L, Augustin MA. Resistant starch modification: effects on starch properties and functionality as co-encapsulant in sodium caseinatebased fish oil microcapsules. J Food Sci 2010; 75 (9): E636-E642.

5. Zhang J, Wang ZW. Optimization of reaction conditions for resistant Canna edulis Ker starch phosphorylation and its structural characterization. Ind Crop Prod 2009; 30(1): 105-113.

6. Pengilly C, García-Aparicio MP, Diedericks D, Görgens J. Optimization of Enzymatic Hydrolysis of Steam Pretreated Triticale Straw. BioEnergy Res 2016; 9(3): 851-863.

7. Ashwar BA, Gani, A, Wani, IA, Shah A, Masoodi FA, Saxena $D C$. Production of resistant starch from rice by dual autoclaving-retrogradation treatment: Invitro digestibility, thermal and structural characterization. Food Hydrocolloid 2016; 56: 108-117.

8. Goni I, Garcia D. Anlysis of resistant starch: a method for foods and food product. Food Chem 1996; 56(4): 445449.

9. Li GL, Liu BG, Zhang GC, Zeng J, Sun JL, Ma HJ . Characterization of Digestion Resistance Sweet Potato Starch Phosphodiester. Trop J Pharm Res 2014; 13 (9): 1393-1400.

10. Teixeira RS, Silva AS, Ferreira-Leitão VS, Bon EP. Amino acids interference on the quantification of reducing sugars by the 3,5-dinitrosalicylic acid assay mislead carbohydrase activity measurements. Carbohydr Res 2012; 363:33-37.

11. Li GL, Li F, Zeng J, Sun JL. Preparation and In vitro Digestibility of Corn Starch Phosphodiester. Trop J Pharm Res 2015; 14 (3): 355-362.

12. Razali MAA, Sanusi $N$, Ismail $H$, Othman $N$, Ariffin $A$. Application of response surface methodology (RSM) for optimization of cassava starch grafted polyDADMAC synthesis for cationic properties. Starch/Stake 2012; 64(12): 935-943.

13. Zabidi MA, Aziz NAA. In vitro starch hydrolysis and estimated glycaemic index of bread substituted with different percentage of chempedak (Artocarpus integer) seed flour. Food Chem 2009; 117(1): 64-68.

14. Chung C, Sanguansri L, Augustin MA. Resistant starch modification: effects on starch properties and functionality as co-encapsulant in sodium caseinatebased fish oil microcapsules. J Food Sci 2010; 75(9): E636-E642 